\title{
Corrigendum
}

\section{Representation and Rights: The Impact of LGBT Legislators in Comparative Perspective—CORRIGENDUM \\ ANDREW REYNOLDS}

doi:10.1017/S0003055413000051, Published online by Cambridge University Press, 21 March 2013

$\mathbf{T}$

he Online Appendix for the article by Reynolds in the May 2013 issue of American Political

Science Review has been updated by the author. It can be found at http://www.journals.cambridge. org/psr2013009.

\section{REFERENCE}

Reynolds, A. "Representation and Rights: The Impact of LGBT Legislators in Comparative Perspective." American Political Science Review 107(2): 259-74. doi:10.1017/S0003055413000051 